\title{
Rare Presentations of Frontal Sinus Fungus Ball: A Systematic Review
}

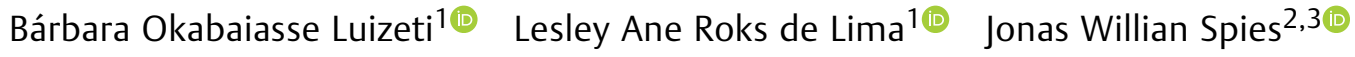 \\ Guilherme Constante Preis Sella1,2,3,4(0) \\ ${ }^{1}$ Department of Medicine, Faculdade de Medicina, Universidade \\ Cesumar, Maringá, Paraná, Brazil \\ 2 Department of Ophthalmology, Otorhinolaryngology, and Head and \\ Neck Surgery, Faculdade de Medicina de Ribeirão Preto, \\ Universidade de of São Paulo (FMRP-USP), Ribeirão Preto, São Paulo, \\ Brazil \\ ${ }^{3}$ Associação Brasileira de Otorrinolaringologia e Cirurgia Cérvico- \\ Facial (ABORL-CCF), São Paulo, São Paulo, Brazil \\ ${ }^{4}$ Academia Brasileira de Cirurgia Plástica da Face (ABCPF), São Paulo, \\ São Paulo, Brazil \\ Int Arch Otorhinolaryngol 2022;26(4):e738-e743. \\ Address for correspondence Bárbara Okabaiasse Luizeti, \\ undergraduate Medicine student, Faculdade de Medicina, \\ Universidade Cesumar, Rua Bragança, 498, Zona 7, Maringá, Paraná, \\ Brazil, CEP 87900-000 (e-mail: baluizeti@gmail.com).
}

\author{
Abstract \\ Keywords \\ - aspergillus fumigatus \\ - communicable \\ diseases \\ - complications \\ - transanal endoscopic \\ surgery \\ - paranasal sinus \\ diseases
}

Introduction The sinus fungus ball is an agglomeration of debris and hyphae, mainly caused by Aspergillus fumigatus, within the paranasal sinus, commonly affecting a single sinus, and it only rarely affects the frontal sinus.

Objective To identify the state of the art of fungus ball in paranasal sinuses, especially related to the epidemiology of the disease in the frontal sinus. Additionally, this article reports a rare case of fungus ball in the frontal sinus in an adult male, and discusses the variables of this condition related to the patient.

Data Synthesis All of the 8 cases of fungus ball in the frontal sinus reported in this study affected male patients: $40 \%$ had unilateral disease, and $60 \%$, bilateral disease, contrary to the incidence data of fungus ball in the other paranasal sinuses, which reports unilateral prevalence. However, in the present study, this index changes, with $50 \%$ of unilateral and $50 \%$ of bilateral incidence regarding frontal sinus involvement. The average age of the patients was 65.36 years (range: $60-74$ years). The etiologic agent was Aspergillus spp., and the endonasal endoscopic therapeutic approach corresponded to $80 \%$ of cases, while frontal osteoplasty accounted for $20 \%$ of cases, reaffirming the prevalence data from other studies.

Conclusion Despite being a low-incidence entity, frontal sinus fungus ball should be considered in patients with pain in the frontal region refractory to the usual clinical treatments. received

February 11, 2021 accepted after revision

September 23, 2021

published online

January 27, 2022
DOI https://doi.org/ 10.1055/s-0041-1740598 ISSN 1809-9777.

\footnotetext{
(C) 2022. Fundação Otorrinolaringologia. All rights reserved. This is an open access article published by Thieme under the terms of the Creative Commons Attribution-NonDerivative-NonCommercial-License, permitting copying and reproduction so long as the original work is given appropriate credit. Contents may not be used for commercial purposes, or adapted, remixed, transformed or built upon. (https://creativecommons.org/ licenses/by-nc-nd/4.0/) Thieme Revinter Publicações Ltda., Rua do Matoso 170, Rio de Janeiro, RJ, CEP 20270-135, Brazil
} 


\section{Introduction}

The sinus fungus ball is defined as an agglomeration of debris and hyphae within the paranasal sinus, commonly affecting a single sinus. ${ }^{1}$ It most commonly affects the maxillary sinus, followed by the sphenoid and ethmoid sinuses, and affection of the frontal sinus is extremely rare, comprising only $\sim 2 \%$ of all involved sinuses. ${ }^{2-4}$ There is a slight predominance of female patients, ${ }^{5}$ and, in most cases, it manifests during the fourth and fifth decades of life, as a result of respiratory infection by Aspergillus spp. ${ }^{6}$

Aspergillus fumigatus and Aspergillus flavus ${ }^{6}$ are the main species involved in fungal rhinosinusitis. Aspergillus is a genus of anamorphic fungi which is characterized by having filamentous fungi with hyaline hyphae, septate and branched at an acute angle. ${ }^{7}$ They thrive in warm climates such as those of tropical countries. Several species of Aspergillus spp. are important to humans due their ability to produce toxic metabolites, mainly A. fumigatus, which forms a fast-growing, bluish-green, and powdery colony. A. flavus, on the other hand, is a filamentous fungus that can produce aflatoxins and cyclopiazonic acid, which makes it toxic to the hosts. ${ }^{8,9}$

Fungal rhinosinusitis comprises between $4 \%$ and $10 \%$ of surgical interventions in the paranasal sinuses, and can be subdivided into invasive and non-invasive. ${ }^{10,11}$ Non-invasive fungal rhinosinusitis is more common in immunocompetent patients, ${ }^{12}$ classified as fungus ball or allergic fungal rhinosinusitis. ${ }^{13}$

The slow and oligosymptomatic development of fungus ball in the frontal sinus often leads to late diagnoses, with the first clinical signs being orbital or intracranial complications. ${ }^{14}$ The diagnosis of fungus ball is difficult, occasionally made through computed tomography (CT) or magnetic resonance imaging (MRI). ${ }^{5,15}$ Surgery with an endonasal endoscopic approach is the treatment of choice. ${ }^{2,16}$

The present systematic review aims to identify the state of the art of fungus ball in the paranasal sinuses, especially related to the epidemiology of the disease in the frontal sinus. Additionally, the present article reports a rare case of fungus ball in the frontal sinus in an adult male, and discusses the variables of this condition related to the patient.

\section{Review of the Literature}

The present is a systematic review and case report written following the Preferred Reporting Items for Systematic Reviews and Meta-Analyzes (PRISMA) statement and its extensions, namely the one for equity-focused reviews (PRISMA-E 2012). ${ }^{17}$ The Population, Intervention, Comparison and Outcome (PICO) system was also followed, but no specific protocols were used in its development.

A search was conducted on the PubMed/MEDLINE, ScienceDirect, BIREME, and Scielo databases by combining the keyword fungus ball with paranasal sinuses, fungal rhinosinusitis, and frontal sinus.

The database search ended on December 13, 2020, with an interval between the months of June and December of the same year.
The inclusion criteria were: prospective and retrospective studies on fungal rhinosinusitis (case reports) and fungus ball in human paranasal sinuses (review articles). The exclusion criteria were studies with in vitro or in animal models, or studies on topics other than that of the present article.

The data extraction process was conducted by two evaluators independently, and any disagreements were solved through consensus or by consulting a third evaluator. We used a pilot-tested spreadsheet developed for the study, in which the reviewers entered the variables of interest. The articles were extracted in duplicate and stored in the bibliographic management software Endnote version 2020 (Clarivate Analytics, Philadelphia, PA, US).

With the aforementioned combinations, 203 articles were found in PubMed/MEDLINE, 889 articles in ScienceDirect, 172 articles in BIREME, and 3 articles in Scielo. After applying the inclusion and exclusion criteria,we selected: 1 article from the Scielo database, 2 from BIREME, and 18 articles from PubMed/MEDLINE, totaling 16 articles on fungus ball in the maxillary, sphenoid, and ethmoid paranasal sinuses, and 5 articles on fungus ball in the frontal sinus. In accordance with the PRISMA-E 2012 statement, the flowchart of the stages of the systematic review can be found in - Fig. 1 .

The most recent studies on fungus ball in paranasal sinuses show the prevalence of fungus ball in paranasal sinuses in the age group of 50 to 60 years. Prospective studies reaffirm the prevalence of fungus ball in the maxillary sinus, followed by the sphenoid, ethmoid, and, finally, the frontal sinuses, reported in the retrospective studies, as well as a higher incidence of cases of unilateral disease and female patients, with the most prevalent etiological agent being Aspergillus spp. The unanimous therapeutic approach of choice is endonasal endoscopy in any affected paranasal sinus.

All the reported cases of fungus ball herein analyzed were in the frontal sinus and affected male patients, which is contrary to the common prevalence of female patients and cases of fungus ball in the other paranasal sinuses. As for thestatistical data, of the 8 patients with fungus ball in the frontal sinus, $40 \%$ had unilateral affection, and $60 \%$, bilateral, which is also contrary to the incidence data for the other paranasal sinuses, which is of unilateral prevalence. However, in the present study, this index changes, with $50 \%$ of unilateral and $50 \%$ of bilateral incidence regarding frontal inus involvement.

As for the etiologic agent Aspergillus spp., the endonasal endoscopic therapeutic approach corresponded to $80 \%$ of the cases, while frontal osteoplasty accounted for $20 \%$ of the cases, reaffirming the prevalence data from other studies. The average age of the patients was 65.36 years, ranging from 60 to 74 years. - Table 1 shows a summary of the data of the reports herein analyzed. $2,14,18-20$

As aforementioned, apart from the systematic review, the present aeticle is also a case report. In a specialized otolaryngology service, a 63-year-old immunocompetent man, with no comorbidities, had as main complaint of "stabbing" pain in the forehead, predominantly on the left side, which had started in the previous 2 months, with no evolution. 


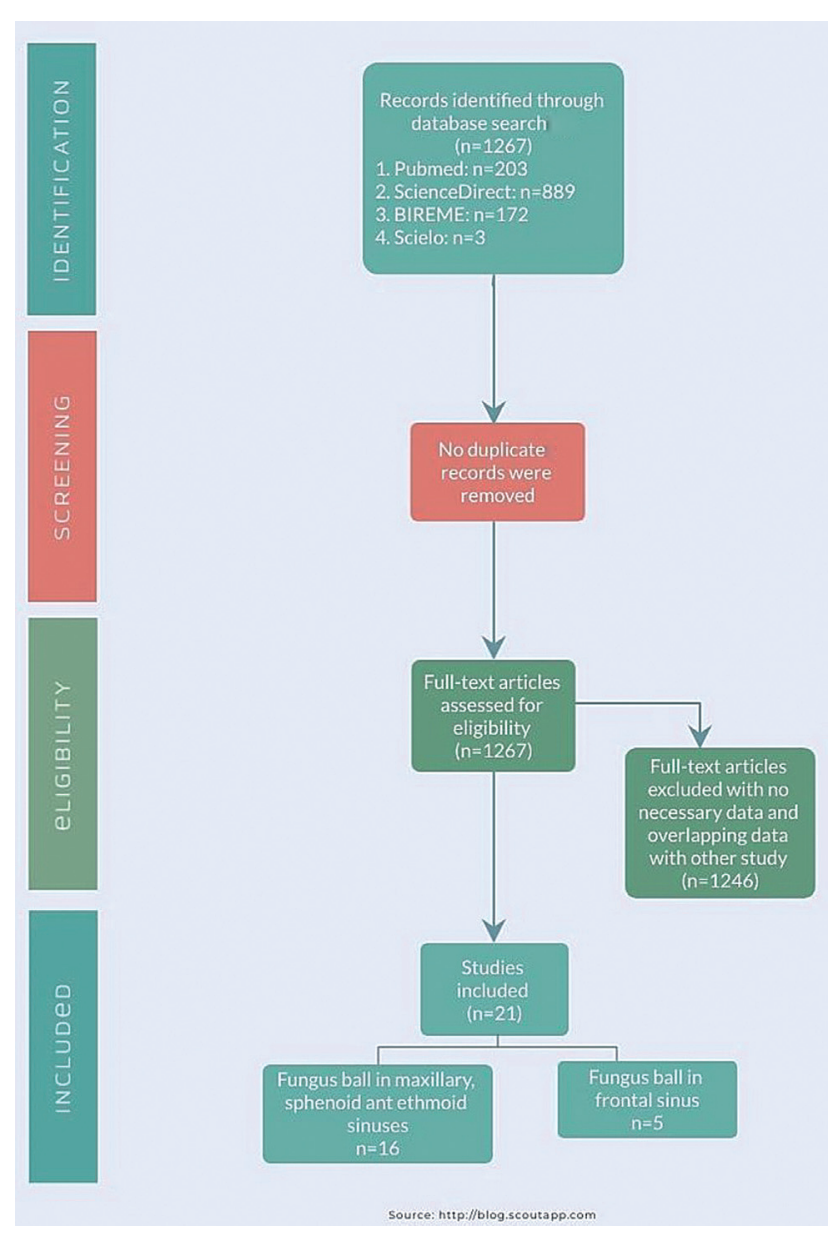

Fig. 1 Flowchart of the different stages of the systematic review.

During this period, the patient used antibiotics, anti-inflammatory drugs, and topical and systemic corticosteroids, with no improvement in his condition.

The initial hypotheses that guided the request for the first exams were of nasal tumors, as well as recurrent acute and chronic rhinosinusitis. There were no abnormalities in the blood and serological tests. The endoscopic examination of the nasal cavity revealed mucosal edema with purulent secretion of the ostiomeatal complex. A CT scan of the paranasal sinuses identified veiling of the frontal sinus with microcalcifications, and hyperattenuating areas associated with bone wall sclerosis, suggestive of fungal bolus
(-Figs. 2 and 3). As these CT findings are typical of fungus balls, there were no differential diagnoses.

The patient underwent maxillary sinusectomy, wide ethmoidectomy, and frontal sinusectomy in accordance with type Ila on the Draf classification, with complete removal of the lesion (-Fig. 4 ). - Fig. 5 shows the endoscopic image of the frontal sinus after removal of a fungus ball. The histologic examination showed sparse fragments of mucosa covered by respiratory epithelium, with edema of the lamina propria and a marked inflammatory infiltrate (lymphocytes, neutrophils, histiocytes, and plasma cells). Intraoperative samples were sent for culture examination. Abundant septate hyphae were dichotomized at an acute angle, compatible with Aspergillus spp., with no signs of malignancy, and the Grocott stain test result was positive for fungi. A biopsy of the healthy frontal sinus mucosa confirmed negative non-invasive fungus ball.

The patient was prescribed: amoxicillin $500 \mathrm{mg}, 1$ tablet every 8 hours for 7 days; prednisolone $20 \mathrm{mg}, 1$ tablet every 12 hours for 5 days; nasal wash with saline $10 \mathrm{ml}$ in each nostril 5 times a day for 30 days; and, if necessary, dipyrone 40 drops, up to every 6 hours, in case of pain.

There were no intraoperative nor postoperative complications. Currently, the patient has been follwed up for one year, and complete improvement of the condition has been observed. The postoperative follow-up was performed by endoscopic control within one year of the surgery, and the nasal patency was preserved without stenosis with Draf IIA sinus drainage. The patient was lost to follow-up right after this last update of his medical record, so it was not possible to photographically record the postoperative period.

\section{Discussion}

Globally, the prevalence of unilateral involvement of paranasal sinuses is higher than the bilateral involvement. However, in the present study this index, related to the frontal sinus fungus ball, is equivalent, corresponding to $50 \%$ of unilateral involvement and $50 \%$ of bilateral involvement, perhaps due to some anatomical alteration in the frontal sinus.

All reported cases of fungus ball in the frontal sinus affected male patients, which goes against the common reported prevalence of the female gender; a possibility for

Table 1 Summary of the main data from the articles retrieved in the systematic review

\begin{tabular}{|c|c|c|c|c|c|}
\hline Reference & $\begin{array}{l}\text { Patients with } \\
\text { fungus ball } \\
\text { in the frontal } \\
\text { sinus }\end{array}$ & $\begin{array}{l}\text { Age at } \\
\text { diagnosis } \\
\text { (years) }\end{array}$ & $\begin{array}{l}\text { Affected } \\
\text { paranasal } \\
\text { sinus }\end{array}$ & $\begin{array}{l}\text { Affection } \\
\text { (unilateral or } \\
\text { bilateral) }\end{array}$ & $\begin{array}{l}\text { Etiological } \\
\text { agent }\end{array}$ \\
\hline Bernardini et al. ${ }^{2}$ (2017) & 2 & $60 ; 65$ & Frontal & Bilateral & Aspergillus fumigatus \\
\hline Popko et al. ${ }^{14}(2010)$ & 2 & $63 ; 74$ & Frontal & Bilateral & Aspergillus fumigatus \\
\hline Seo et al. ${ }^{18}(2019)$ & 1 & 61.16 & Frontal & Unilateral (left) & Aspergillus spp. \\
\hline Wei et al. ${ }^{19}(2016)$ & 2 & - & Frontal & Bilateral & Aspergillus spp. \\
\hline Stevens $^{20}$ (1978) & 1 & 69 & Frontal & Unilateral (right) & Aspergillus fumigatus \\
\hline
\end{tabular}




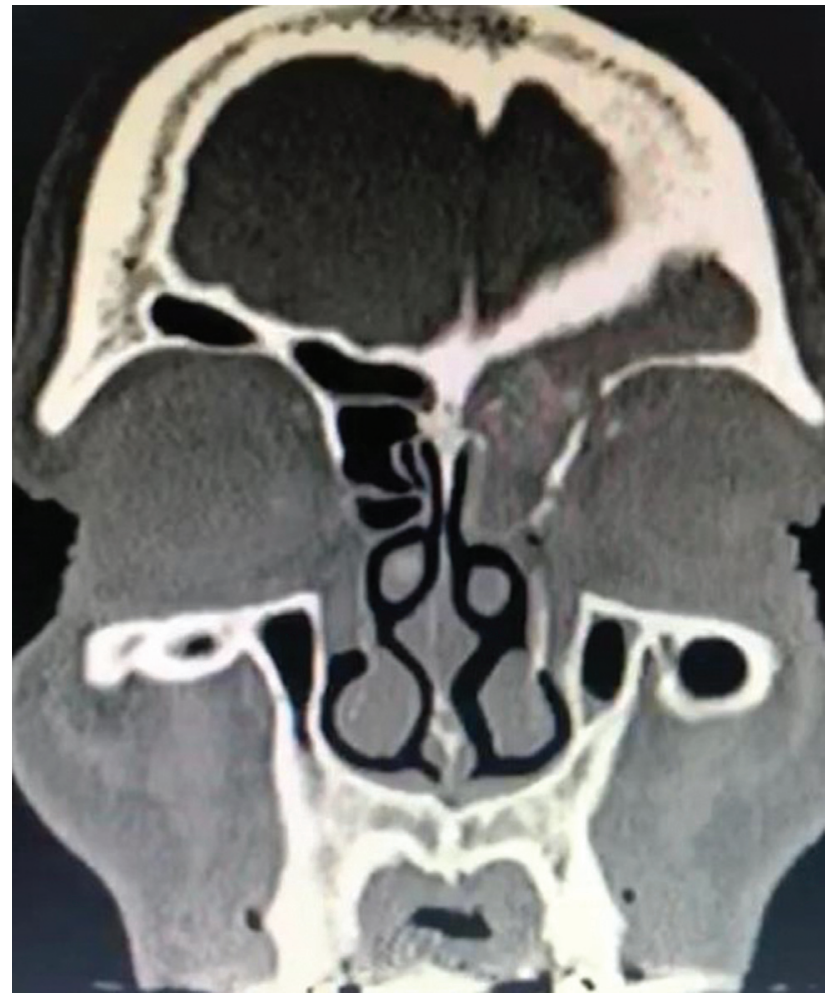

Fig. 2 Computed tomography scan in sagittal view showing obliteration with frontal sinus microcalcifications.

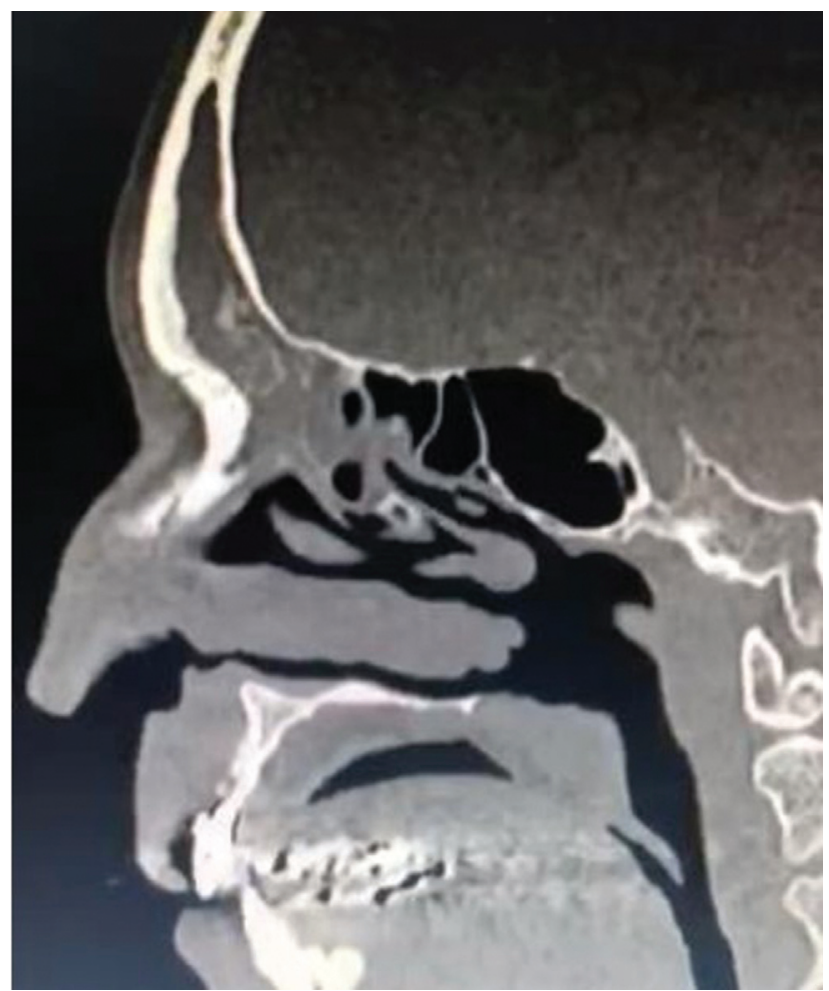

Fig. 3 Computed tomography scan in coronal view showing complete and heterogeneous left opacification of the frontal sinus.

this gender difference may be hormonal. The average age of the reported cases was of 65.36 years (range: 60 to 74 years), which exceeds the age range commonly reported in other

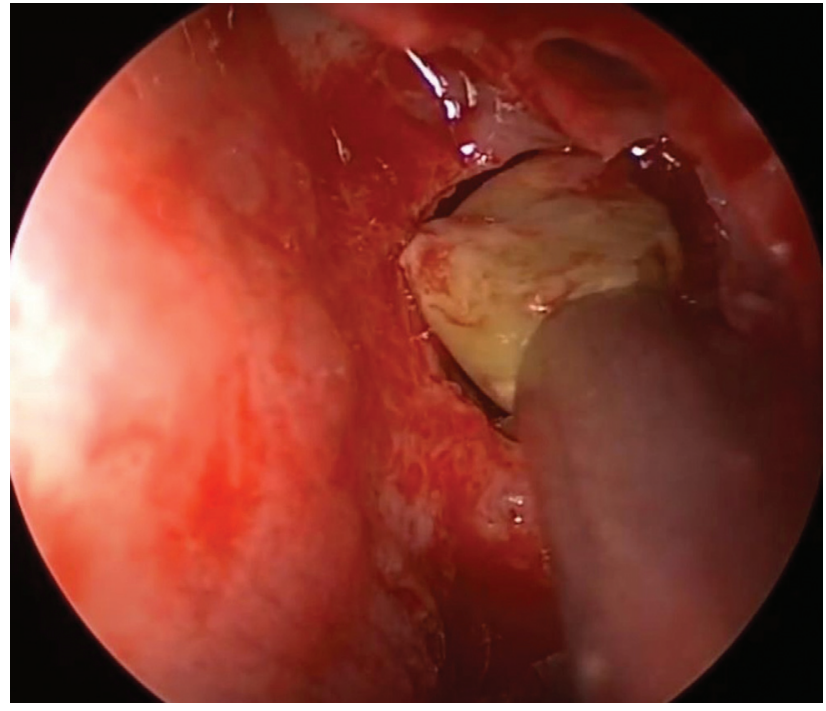

Fig. 4 Endoscopic removal of a fungus ball from the frontal sinus.

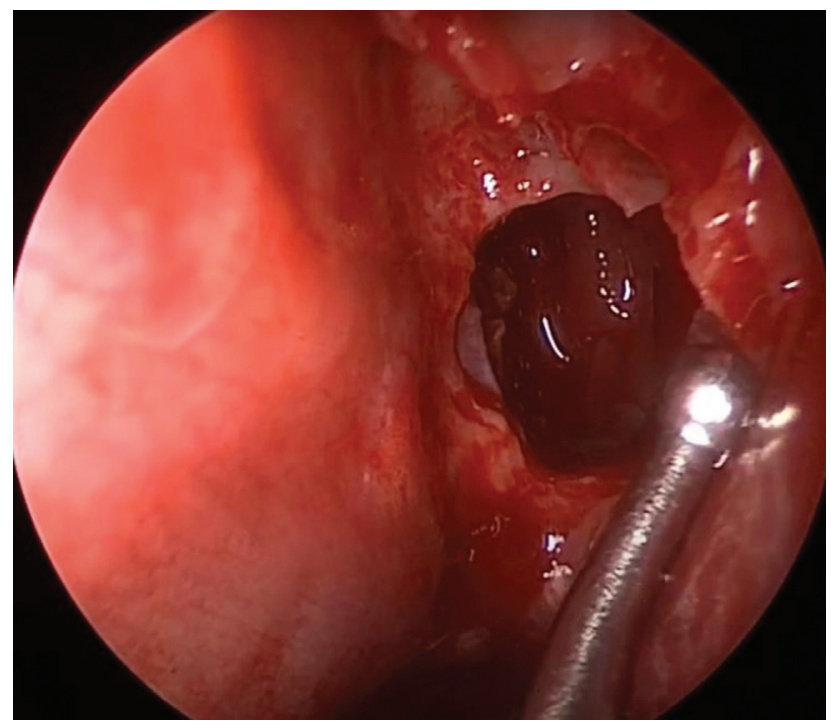

Fig. 5 Endoscopic image showing the frontal sinus after removal of a fungus ball.

cases of fungus balls in the paranasal sinuses; the fact that it occured in older patients may be related to the delay in the proliferation of fungi, reaching more patients in this age group. $^{21}$

The aerogenic hypothesis ${ }^{22}$ suggests that fungal spores reach the mucosa by inhalation and acquire pathogenic capacity due to anaerobic conditions within the sinus. ${ }^{4}$ Other authors ${ }^{23}$ indicate that obstruction of the osteomeatal complex or chronic rhinosinusitis are predisposing factors for fungus ball. However, this theory does not explain the cases of fungus ball that affect the sphenoid or frontal sinuses. ${ }^{23,24}$ Not all patients with occluded frontal sinuses develop a fungus ball, which probably means that spores are not always able to reach the frontal sinus due to the complex anatomy of the frontal recess. ${ }^{23,24}$ 
Of the several anatomical sinonasal variants that may be related to this pathogenesis, the presence of bullous shell was significantly associated with the development of fungus ball, as well as a narrow infundibulum and anatomical variations in the region of the ostiomeatal complex, known to cause sinus hypoventilation. ${ }^{25}$ Concomitant to this, our patient's anterior ethmoidal cells obstructed the frontal recess, which may explain the pathophysiological mechanism.

Imaging plays an important role in the diagnosis of fungal sinus disease. The initial imaging study of choice in most cases is the CT scan. Due to the nonspecific nature of many of the imaging findings, CT scans alone cannot be relied on to make the diagnosis, which requires a high index of clinical suspicion. Another option is the MRI, which can better delineate invasive disease involving the soft tissues beyond the sinuses; therefore, the performance of MRI scans is recommended if malignancy is suspected. ${ }^{14,26,27}$ In the case herein reported, only CTwas used, as it offered sufficient diagnostic criteria to perform the therapeutic procedure, according to the preclinical and surgical evaluations.

Endonasal endoscopy is the therapeutic approach of choice for any condition affecting the paranasal sinuses, as the pharmacological treatment alone does not result in improvement. It was the approach used in $80 \%$ of the cases in the present study, while frontal osteoplasty was reserved only for those in whom the endonasal approach was not possible.

The extended frontal approaches, described by Draf, Lothrop and Gross, can improve the surgical results and long-term nasal patency of the frontal sinus. ${ }^{27,28}$ The Draf I procedure enables the endoscopic access to the frontal recess, and is recommended for cases in which the frontal sinus pathology persists despite the use of the conservative technique to access the infundibulum and the anterior ethmoidal region. This procedure involves complete removal of the posterior ethmoidal cells and the uncinate process. If present, obstructive anterior cells are removed. ${ }^{29-31}$

The Draf II procedure involves endoscopic frontal sinusotomy, and is recommended for patients with severe or chronic forms of frontal disease in whom removal of the inflammatory or benign neoformations in the middle frontal sinus has failed after the endoscopic access to the frontal recess. In the Draf IIA procedure, the frontal sinus floor is resected from the lamina papyracea to the middle turbinate, whereas in Draf IIB, the frontal sinus floor is resected from the lamina papyracea to the nasal septum. In both cases, the posterior limit of the resection is the ventral margin of the nasal fossa. ${ }^{28-31}$ Dissection involves the removal of the anterior face from the frontal recess; thus, the frontal ostium is increased to the maximum dimension. ${ }^{28,30}$

Regarding the preference between the two techniques, Draf IIB was indicated when the initial opening of Draf IIA was considered insufficient and prone to postoperative stenosis, or when an additional access was required due to the presence of tumors and mucoceles. ${ }^{30,31}$ In the case herein reported, a second approach with Draf IIB was not necessary, as the nasal patency was preserved without stenosis after Draf IIA.
Finally, Draf III is a modification of the surgery idealized by Lothrop, and is indicated in case of severe, chronic sinusitis. This technique combines a bilateral Draf IIB procedure with resection of the frontal intersinus septum and a section of the nasal septum, which forms a common frontal cavity. ${ }^{31,32}$ For the sake of a more comprehensive discussion on the different approaches to the frontal sinus, it should be noted that there are minimally-invasive techniques to manage lesions that are not amenable to complete resection via the Draf type-II or -III approaches, such as the endoscopic orbital transposition ${ }^{33}$ and transorbital approaches. ${ }^{34}$

Many important neurovascular structures are adjacent to the frontal sinus, putting the patient at risk of orbital and intracranial complications. Thus, early diagnosis and surgical intervention are essential.

The validity of the conclusion and statistical analysis regarding the frontal sinus mycetoma is affected due the small number of cases included in the present study and reported in the scientific literature, in which case reports predominate over studies with large samples.

\section{Final Comments}

The presence of a fungus ball in the frontal sinus, even if noninvasive, is potentially much more serious when compared with cases involving other sinuses. Despite its low incidence, frontal sinus fungus ball should be considered in patients with pain in the frontal region who do not respond to the usual clinical treatments. The present study demonstrated the general epidemiological characteristics of this condition, contributing to the update of this differential diagnosis in otorhinological care.

Conflict of Interests

The authors have no conflict of interests to declare.

\section{References}

1 Jun YJ, Shin JM, Lee JY, Baek BJ. Bony Changes in a Unilateral Maxillary Sinus Fungal Ball. J Craniofac Surg 2018;29(01): e44-e47

2 Bernardini E, Karligkiotis A, Fortunato S, Castelnuovo P, Dallan I. Surgical and pathogenetic considerations of frontal sinus fungus ball. Eur Arch Otorhinolaryngol 2017;274(06):2493-2497

3 Chakrabarti A, Denning DW, Ferguson BJ, et al. Fungal rhinosinusitis: a categorization and definitional schema addressing current controversies. Laryngoscope 2009;119(09):1809-1818

4 Grosjean P, Weber R. Fungus balls of the paranasal sinuses: a review. Eur Arch Otorhinolaryngol 2007;264(05):461-470

5 Yoon YH, Xu J, Park SK, Heo JH, Kim YM, Rha KS. A retrospective analysis of 538 sinonasal fungus ball cases treated at a single tertiary medical center in Korea (1996-2015). Int Forum Allergy Rhinol 2017;7(11):1070-1075

6 Pagella F, Pusateri A, Matti E, et al. Sphenoid sinus fungus ball: our experience. Am J Rhinol Allergy 2011;25(04):276-280

7 Borges VB, Couto MAPG, Souza MCL, Moraes AML, Xavier MMBBS. Macro and micro-structural study on aspergillus parasiticus inoculated in peanut kernels treated with gamma radiation (Cs137). J Bioen Food Sci. 2017;4(01):68-77

8 Kwon-Chung KJ, Sugui JA. Aspergillus fumigatus-what makes the species a ubiquitous human fungal pathogen? PLoS Pathog 2013; 9(12):e1003743 
9 Hope WW, Petraitis V, Petraitiene R, Aghamolla T, Bacher J, Walsh TJ. The initial 96 hours of invasive pulmonary aspergillosis: histopathology, comparative kinetics of galactomannan and $(1->3) \beta$-d-glucan and consequences of delayed antifungal therapy. Antimicrob Agents Chemother 2010;54(11):4879-4886

10 Ledderose GJ, Braun T, Betz CS, Stelter K, Leunig A. Functional endoscopic surgery of paranasal fungus ball: clinical outcome, patient benefit and health-related quality of life. Eur Arch Otorhinolaryngol 2012;269(10):2203-2208

11 Nicolai P, Lombardi D, Tomenzoli D, et al. Fungus ball of the paranasal sinuses: experience in 160 patients treated with endoscopic surgery. Laryngoscope 2009;119(11):2275-2279

12 Lim HS, Yoon YH, Xu J, Kim YM, Rha KS. Isolated sphenoid sinus fungus ball: a retrospective study conducted at a tertiary care referral center in Korea. Eur Arch Otorhinolaryngol 2017;274(06): 2453-2459

13 Katzenstein AL, Sale SR, Greenberger PA. Allergic Aspergillus sinusitis: a newly recognized form of sinusitis. J Allergy Clin Immunol 1983;72(01):89-93

14 Popko M, Broglie MA, Holzmann D. Isolated fungus ball mimicking mucocele or frontal sinus tumour: a diagnostic pitfall. J Laryngol Otol 2010;124(10):1111-1115

15 Ho CF, Lee TJ, Wu PW, et al. Diagnosis of a maxillary sinus fungus ball without intralesional hyperdensity on computed tomography. Laryngoscope 2019;129(05):1041-1045

16 Klossek JM, Serrano E, Péloquin L, Percodani J, Fontanel JP, Pessey JJ. Functional endoscopic sinus surgery and 109 mycetomas of paranasal sinuses. Laryngoscope 1997;107(01):112-117

17 Welch V, Petticrew M, Petkovic J, et al; PRISMA-Equity Bellagio group. Extending the PRISMA statement to equity-focused systematic reviews (PRISMA-E 2012): explanation and elaboration. J Clin Epidemiol 2016;70:68-89

18 Seo MY, Lee SH, Ryu G, et al. Clinical pattern of fungal balls in the paranasal sinuses: our experience with 70 patients. Eur Arch Otorhinolaryngol 2019;276(04):1035-1038

19 Wei X, Nian JB, Wang G, Zhang YL, Cai SE, Liu SZ. [Clinic characters analysis of 52 cases with sinus fungus ball disease]. Lin Chung Er Bi Yan Hou Tou Jing Wai Ke Za Zhi 2016;30(22): 1754-1757Chinese.

20 Stevens MH. Aspergillosis of the frontal sinus. Arch Otolaryngol 1978;104(03):153-156

21 Dufour X, Kauffmann-Lacroix C, Ferrie JC, Goujon JM, Rodier MH, Klossek JM. Paranasal sinus fungus ball: epidemiology, clinical features and diagnosis. A retrospective analysis of 173 cases from a single medical center in France, 1989-2002. Med Mycol 2006;44 (01):61-67

22 Milosev B, el-Mahgoub S, Aal OA, el-Hassan AM. Primary aspergilloma of paranasal sinuses in the Sudan. A review of seventeen cases. Br J Surg 1969;56(02):132-137

23 Tsai TL, Guo YC, Ho CY, Lin CZ. The role of ostiomeatal complex obstruction in maxillary fungus ball. Otolaryngol Head Neck Surg 2006;134(03):494-498

24 Dassi CS, Demarco FR, Mangussi-Gomes J, Weber R, Balsalobre L, Stamm AC. The Frontal Sinus and Frontal Recess: Anatomical, Radiological and Surgical Concepts. Int Arch Otorhinolaryngol 2020;24(03):e364-e375

25 Shin JM, Baek BJ, Byun JY, Jun YJ, Lee JY. Analysis of sinonasal anatomical variations associated with maxillary sinus fungal balls. Auris Nasus Larynx 2016;43(05):524-528

26 Ni Mhurchu E, Ospina J, Janjua AS, Shewchuk JR, Vertinsky AT. Fungal Rhinosinusitis: A Radiological Review With Intraoperative Correlation. Can Assoc Radiol J 2017;68(02):178-186

27 Weber R, Draf W, Kratzsch B, Hosemann W, Schaefer SD. Modern concepts of frontal sinus surgery. Laryngoscope 2001;111(01): 137-146

28 Gross WE, Gross CW, Becker D, Moore D, Phillips D. Modified transnasal endoscopic Lothrop procedure as an alternative to frontal sinus obliteration. Otolaryngol Head Neck Surg 1995;113 (04):427-434

29 Naidoo Y, Bassiouni A, Keen M, Wormald PJ. Long-term outcomes for the endoscopic modified Lothrop/Draf III procedure: a 10-year review. Laryngoscope 2014;124(01):43-49

30 Ting JY, Wu A, Metson R. Frontal sinus drillout (modified Lothrop procedure): long-term results in 204 patients. Laryngoscope 2014;124(05):1066-1070

31 Draf W. Endonasal Frontal Sinus Drainage Type I-III According to Draf. (eds) The Frontal Sinus. 2005SpringerBerlin, Heidelberg

32 Turner JH, Vaezeafshar R, Hwang PH. Indications and outcomes for Draf IIB frontal sinus surgery. Am J Rhinol Allergy 2016;30(01): 70-73

33 Karligkiotis A, Pistochini A, Turri-Zanoni M, et al. Endoscopic endonasal orbital transposition to expand the frontal sinus approaches. Am J Rhinol Allergy 2015;29(06):449-456. Doi: 10.2500/ajra.2015.29.4230

34 Arosio $\mathrm{AD}$, Coden $\mathrm{E}$, Valentini $\mathrm{M}$, et al. Combined endonasaltransorbital approach to manage the far lateral frontal sinus: surgical technique Multiportal approach to frontal sinus. World Neurosurg 2021;151:5. Doi: 10.1016/j.wneu.2021.04.017 